\title{
Efficiency in Use of Oil as Fuel
}

\author{
By W. N. Best, D. Sc., New York, N. Y.
}

(St. Louis Meeting, September, 1920)

THIS paper is not intended as a scientific discussion of the combustion of oil but is written from the standpoint of an operator who has the experience and qualifications necessary to guide others in producing the most economical results in the use of liquid fuels. Oil, in this paper, usually means petroleum or its products but incidental reference is made to other liquid and gaseous fuels, so that the term may be considered as referring to all liquid and gaseous hydrocarbons in comparison with solid fuels, as coal and wood. However, only a few of the principal factors in the use of oil as a fuel can be given.

The present, and prospective, high price of coal is causing users of fuel to renew inquiry as to the merits of other forms of fuel for industrial purposes. Crude oil (petroleum) is proving to be one of the world's most valuable mineral resources. The recent discovery that oil underlies a considerable area of the United States, Mexico, and other parts of the world to a greater extent than was formerly believed and the large production of some of the wells in these areas shows the probable quantity of fuel oil that may now be available. Through the encrgy of Lord Cowdrey, who was one of the pioneers of the oil industry in Mexico, oil has been discovered in England; some prominent geologists believe that it may be found in quantity in Great Britain.

For years, oil has been known to be of great value in the manufacture of metals. It has proved incomparable in forge shops, steel foundries, heat-treating furnaces, and wherever accuracy of temperatures is essential, or where a maximum output is desired as well as quality of metal. In some types of equipment, the output produced with oil as fuel is double that obtained with coal and at a reduction of 50 per cent. in the cost of the fuel. For example, in drop-forging plants, the metal is always waiting for the man when oil is used as fuel, whereas with coal, the man must wait for the metal to become sufficiently heated.

It has only been since January, 1919, that the oil supply could be relied on for boiler service, owing to the war conditions and the inability to get oil tankers for the delivery of the oil from Mexico to Atlantic ports; but now a constant supply is assured, and many manufacturers are installing it in their power plants. The cost varies with the size of the 
plant. In New England and along the Atlantic coast, where the boiler horsepower is large, this fuel is very attractive, for one man can fire and water-tend twelve $300-\mathrm{hp}$. boilers. It raises the general condition of the man firing the boilers, because the burning of oil is an art and necessitates brain rather than brawn. This fuel responds immediately to the will of the operator in meeting peak or fluctuating loads. The fire room is clean and sanitary, dust from coal and ashes being eliminated. There is practically no loss in fuel, as only a small part of the oil in the storage tank is heated, and that just enough for it to be pumped readily from the storage tank to the supply tank. The handling of the fuel is inexpensive; and it is speedily delivered from the oil tank or tanker. There are, however, certain fundamental principles that must always be observed in making crude-oil installations.

\section{Temperature of Fuel}

The temperature of the fuel and the method of supply are especially vital points. Oil below $20^{\circ}$ Bé should be heated to just below its vaporizing point; steam should always be used for this purpose, as it gives a very accurate temperature; the supply is usually obtained from the exhaust of the pump. Numerous efforts have been made to heat the oil, while passing through the pipes, by electric currents and by heat from coke, gas, and oil fires; these methods have always proved inferior to steam.

Thermometers should always be used, for the manufacturer who heats his fuel accurately and uniformly every day is the one who obtains the greatest efficiency from the fuel burned.

\section{SUPPLY LINES}

Supply lines should be so laid as to insure the constant circulation of fuel through all the oil-supply pipes from the pump to the burners. A pressure relief valve should always be placed at the farther end of the burner installation, and the overflow pipe should always return the unused fuel to the supply tank. This is imperative especially when using heavy oils, as they must be heated to reduce their viscosity. Many people have put in a large oil main and run laterals from the main to the boilers or furnaces. Then when a boiler must be washed out or a furnace is shut down for repairs, the oil solidifies in the oil pipe or, if it does not solidify, the residuum from the oil collects in these pipes, causing annoyance and unnecessary trouble. The locating of the oil-storage tank and the laying out of the pipe lines are engineering feats, just as much as the equipment of the boilers or furnaces.

The oil pumps should be brass lined. Two should always be provided, one being held in reserve for use in cases of any emergency. Air chambers 
and pressure gages should be used; the former to reduce the pulsations caused by the displacement of the oil by the piston and the latter to record the oil pressure maintained upon the oil-supply line. The spring of the pressure-relief valve should be very sensitive, in order that it may release quickly without causing a variation of more than $1 / 4 \mathrm{lb} .(0.14 \mathrm{~kg}$.) pressure on the oil supply to the burners. Oil meters should be used whenever possible; the foreman of a boiler plant or furnace department provided with these instruments is encouraged to see that the strictest economy in fuel is maintained.

\section{Types of Burners and Their Use}

Numerous oil burners are on the market but the three types most common are: The external atomizing type, which is largely used in locomotive and stationary boilers and in large furnaces; the internal atomizing type, which is chiefly used on small furnaces; and the mechanical type of burner used on ocean-going vessels, which forces the oil at high pressure through a small aperture, thus making a funnel-shaped flame. This type of burner is used on ocean vessels because no steam is required for atomizing, consequently there is no loss of water. This saving in water, however, is accompanied by loss in fuel, for more oil is required to replace a ton of coal while using a mechanical burner than with the external atomizing burner, because a mechanical burner cannot atomize the fuel. For example, 180 gal. $(681$ 1.) of oil is the equivalent of a long ton of coal (calorific value, 14,000 B.t.u. per lb.) when using a mechanical burner; while with the use of an atomizing burner only $147 \mathrm{gal}$. of oil is the equivalent.

When purchasing atomizing burners, several points should always be considered.

1. The burner must not carbonize. A burner that carbonizes should be scrapped at once, as it is not dependable, is wasteful of oil, and requires a great deal of care and attention. Such a burner reduces the burning of oil from a science to a continuous hazard and care.

2. The oil and steam orifices should be independent of each other so that excessive oil pressure is not required and so that no cutting effect is produced when burning oil containing residuum or sand.

3. The burner should be so constructed and filed that it will produce a flame of sufficient length and width to fill the combustion chamber of the furnace or firebox of boiler; in fact, just as perfectly as a drawer fits into its opening in a desk.

4. The oil orifice should be large cnough to permit free exit of heavy oils and tars therefrom, and the atomizer opening should be as small as possible in order to reduce to a minimum the amount of steam or compressed air used for the atomization of the fuel. 
For boiler equipments, steam is preferable as an atomizing agent if $20 \mathrm{lb}$. (9 kg.) pressure or more is carried upon the boiler; but for smaller pressures air should be used. For furnace equipments, air is preferable to steam for atomizing purposes as it reduces to a minimum the amount of moisture in the furnace.

Today boiler settings are demanded that give ample room for combustion. Boilers for 300 degrees overload are being set with a distance of $14 \mathrm{ft}$. ( $4.3 \mathrm{~m}$.) from the coal stokers to the elements of the boiler. When burning oil, the larger the combustion chamber (up to a certain limit), the greater is the efficiency obtained from the fuel and the higher is the boiler horsepower rating obtained. Recording $\mathrm{CO}_{2}$ instruments should be used in order to gage the air supply accurately and prevent loss of fuel through excessive air supply. For furnace equipments, pyrometers are essential.

Mexican oil is high in sulfur, often containing as much as 3.8 per cent. It is therefore necessary that a combustion chamber be used on furnaces so that the atomized oil may be consumed before it reaches the furnace proper. In boilers there is no difficulty because of sulfur, no matter of what material the stock is made. The question is often asked, "Do steel stacks deteriorate from the use of oil containing as high a percentage of sulfur as Mexican oil?" There will be no deterioration unless the stack temperature reaches $850^{\circ} \mathrm{F}$. In ordinary boiler practice, there is, therefore, no likelihood of any detrimental effect because the stack temperatures do not reach so high a degree. Many people condemn the use of this fuel in furnaces because their furnaces do not have combustion chambers to consume the sulfur; when this is consumed in the furnace, there is a detrimental effect upon the metal and the odor in the shop causes the men to complain. In open-hearth furnace work, it has been found good practice to use the lighter oils until the charge is brought down and is covered with slag, after which the Mexican oil can be used with no detrimental effect upon the metal.

\section{Cost of Operating with OiL and Coal}

Many engineers and manufacturers take the calorific value of the oil and the calorific value of the coal as bases from which to estimate the difference in cost of operating with these two fuels. This should not be done as the figures thereby obtained are incorrect.

In flue-welding furnaces, $58 \mathrm{gal}$. of oil is the equivalent of a long ton of coal $(2240 \mathrm{lb}$.) due to the fact that in welding with coal, for safeending the flue, it is necessary to coke the fire; this not only means a loss of time but also a loss of the volatile hydrogen and hydrocarbon gases, much of the calorific value of the fuel. These gases are utilized in boiler practice; here the economy effected depends largely on the size of the 
plant, for one man can fire and water-tend a battery of twelve oil-fired boilers almost as easily as he can care for one boiler. With proper equipment, the tonnage of a locomotive is increased 15 per cent. when changed from coal to oil.

The equivalent of one long ton of coal, in the average locomotive service, is 180 gal. oil; in the average stationary boiler practice, $147 \mathrm{gal}$.; in forging furnaces, $80 \mathrm{gal}$; in heat-treating furnaces, with low temperatures, $80 \mathrm{gal}$; and in heat-treating furnaces with high temperatures and annealing furnaces, $63 \mathrm{gal}$. In working these figures, it must be noted that, in each instance quoted, the oil has a calorific value of 19,000 B.t.u. per lb. and weighs $71 / 2 \mathrm{lb}$. per gal. while the coal averages 14,200 B.t.u. per lb. and weighs $2240 \mathrm{lb}$. per ton.

$31 / 4 \mathrm{bbl}$. oil ( $42 \mathrm{gal}$. per bbl.) is the equivalent of $5000 \mathrm{lb}$. hickory or $4550 \mathrm{lb}$. white oak.

6 gal. oil equals $1000 \mathrm{cu}$. $\mathrm{ft}$. of natural gas of calorific value of 1000 B.t.u. per cu. ft.

$3 \frac{1}{2}$ gal. oil equals $1000 \mathrm{cu}$. ft. of commercial or water gas of calorific value of 620 B.t.u. per cu. $\mathrm{ft}$.

$21 / 4$ gal. oil equals $1000 \mathrm{cu}$. ft. byproduct coke-oven gas at 440 B.t.u. per cu. ft.

0.42 gal. oil equals $1000 \mathrm{cu}$. ft. blast-furnace gas at 90 B.t.u. per cu. ft.

Steel works are now utilizing their blast-furnace gases, which are of low calorific value, being on an average but 90 B.t.u. per cu. ft. For this reason, it is customary, when these gases are used in boilers, large furnaces, etc., to use an auxiliary fuel in combination therewith. This auxiliary fuel is usually coal tar (the byproduct of coke ovens); this makes a fine combination. Usually $10 \mathrm{gal}$. of coal tar are made from every ton of coal coked in byproduct coke ovens; this tar has a calorific value of 162,000 B.t.u. per gal. When this coal tar is not available, crude oil is used.

Efforts have been made in West Virginia lately to retain within its border all the natural gas produced in that state. If those fostering this movement succeed, within a period of two years there will be scarcely any natural gas used in the states of Indiana, Ohio, and Pennsylvania. The small quantity of natural gas produced in these three states will be used for domestic or houschold purposes, rather than in furnaces, etc. Oil, therefore, is the fuel that will be used as it is particularly adapted for furnaces in which natural gas was originally used.

\section{DISCUSSION}

S. O. Andros, * Chicago, Ill.- The most important thing in the burning of fuel oil is the design of the furnace. Almost any of the good burners on the market will be efficient, if the furnace is properly designed.

* Editor, Oil News. 
Without proper furnace design, it is impossible to get efficient operation of the burner. The burner itself is not so much of an item in the domestic field as the assembling of the system for domestic use.

Ralph R. Matthews, * Wood River, Ill.--In 1911, when connected with the Bureau of Mines, I inspected various installations of fuel oil burners in Seattle, Portland, and San Francisco and found that every engineer had his pet type. The results seemed to show that as long as the oil is atomized properly, the manner in which it is atomized is not of great importance, but that the furnace must be properly designed. When the furnace design is not proper, there is overheating and probably excessive stack temperature due to burning a larger quantity of fuel oil than should be necessary. Conservation of fuel oil is thus closely linked with furnace design.

Henry P. Mueller, $†$ St. Louis, Mo.-I am connected with a bras foundry that makes 15 tons of metal daily, burning 1000 gal. of oil. In the last ten years we have tried practically every burner on the market, but the most satisfactory was one we designed. The oil is discharged as a spray under 21/2-lb. pressure; the air comes out of the 11/2-in. opening and breaks up the oil at the end of the burner, throwing it $18 \mathrm{in}$. before it enters the furnace.

Some of our burners are running under compressed air, which in some cases is more economical than steam. The oil is run into the tanks under air pressure and is left in circulation; as a result, it is unnecessary to clean a burner or pipe.

The furnace is of the revolving type. The flame does not come into contact with the metal; instead it heats the top of the furnace, then as that is revolved under the charge, the metals are melted with a loss of only $1 \frac{1}{2}$ per cent.

The cost of melting metal on a normal market is 14 cents; today we are paying 10 cents per gallon for oil in carload lots, therefore the cost of melting is practically doubled.

John L. Henning, Lake Charles, La.-In burning oil we have not had much difficulty in getting proper atomization. The furnace design is the most important thing. We used a common burner and tried to get a happy medium between good combustion and long lived furnace. We burned Mexican oil straight without any trouble with that type burner. When the price of kerosene was low, we burned it in the same burners, simply letting it run out, and got as good combustion as with crude oil under the best conditions.

\footnotetext{
* Chief Chemist, Roxana Petroleum Corpn.

$\dagger$ President, Mueller Brass Foundry.
} 
ARThUR KNapp, Shreveport, La.-In burning oil in small quantities it is necessary to remember that oil must be brought into a condition to ignite; that is, each particle must be vaporized before it will burn. When burning a small quantity, as trying to fire a 10-hp. boiler or smaller, it is necessary to have a large surface that will radiate sufficient heat to vaporize the oil and ignite the vapor. In large furnaces, large radiating surfaces above or to the side of the burner furnish the required heat.

W. N. BEST (author's reply to discussion).-While it is important to have the furnace properly designed, if the oil burner will not function with the furnace design, there will be inefficient combustion; vice versa, if the furnace is improperly designed, the most efficient and most modern type of burner will be a failure.

Mr. Mathews is perfectly correct in his premises of a proper design of furnace, but it is just as essential to have a burner that will not carbonize; that will atomize any gravity of liquid fuel; that does not require excessive oil pressure. It is very important, in burning heavy oil or tars to use low oil pressure. Oil or tar should never be burned under an oil or tar pressure exceeding $12 \mathrm{lb}$., using an atomizing burner.

In the melting of brass it is absolutely essential to have a properly designed furnace; to have a combustion chamber of adequate proportions to insure the consumption of the atomized fuel and the reduction of it to heat before it reaches the furnace proper; to have a burner that will make a flame to fit the combustion chamber as perfectly as a drawer fits an opening in a desk. Without the combustion chamber the furnace will not function properly, owing to the fact that there will be an excessive amount of unmixed air entering the furnace, which will result in an excessive loss of metal. 